\title{
Posterior mediastinal Castleman's disease with vascular malformation
}

\author{
Ayalew T. Tamire \\ Department of Surgery, Addis Ababa University, Addis Ababa, Ethiopia \\ Correspondence: ayalewt12@gmail.com
}

(c) 2018 A.T. Tamire. This open access article is licensed under a (reative Commons Attribution 4.0 International License (http://creativecommons.org/licenses/by/4.0/), which permits unrestricted use, distribution, and reproduction in any medium, provided you give appropriate credit to the original author(s) and the source, provide a link to the Creative Commons license, and indicate if changes were made.

East Cent Afr J Surg. 2018 Aug;23(2):76-79 https://dx.doi.org/10.4314/ecajs.v23i2.5

\begin{abstract}
Castelman's disease (CD) is a rare lymphoproliferative disorder of unknown aetiology, with the unicentric form usually involving the chest. Posterior mediastinal involvement is uncommon, exceedingly so when associated with vascular malformation. We report the case of a young female patient who presented with 9 months of left-sided, dull chest and flank pain associated with weight loss and a subjective tingling sensation. Imaging reveled a well-circumscribed hyper-enhancing posterior mediastinal para-oesophageal mass. She underwent a right posterolateral thoracotomy, mass excision. Histopathologic examination confirmed Castleman's disease (CD) with arteriovenous malformation.

CD with vascular malformation is a very rare condition that can only be diagnosed histopathologically. Surgical resection is effective and has a good prognosis.
\end{abstract}

Keywords: Castleman's disease, AV malformation, posterior mediastinum

\section{Introduction}

Castleman's Disease (CD) is a rare benign lymphoproliferative disorder involving hyperplasia of lymph tissue in 2 distinct disease patterns-unicentric or multicentric. Histologically, 3 variants are described: hyaline vascular, plasmacytic, or with mixed cellularity. ${ }^{1}$ Unicentric disease commonly presents as an asymptomatic mass in proximity to the tracheobronchial tree or hilum. Posterior mediastinal involvement is exceedingly rare, ${ }^{2}$ as is $\mathrm{CD}$ complicated by vascular malformation. We present a case of $\mathrm{CD}$ with vascular malformation in the posterior mediastinum of a 26-year-old symptomatic female.
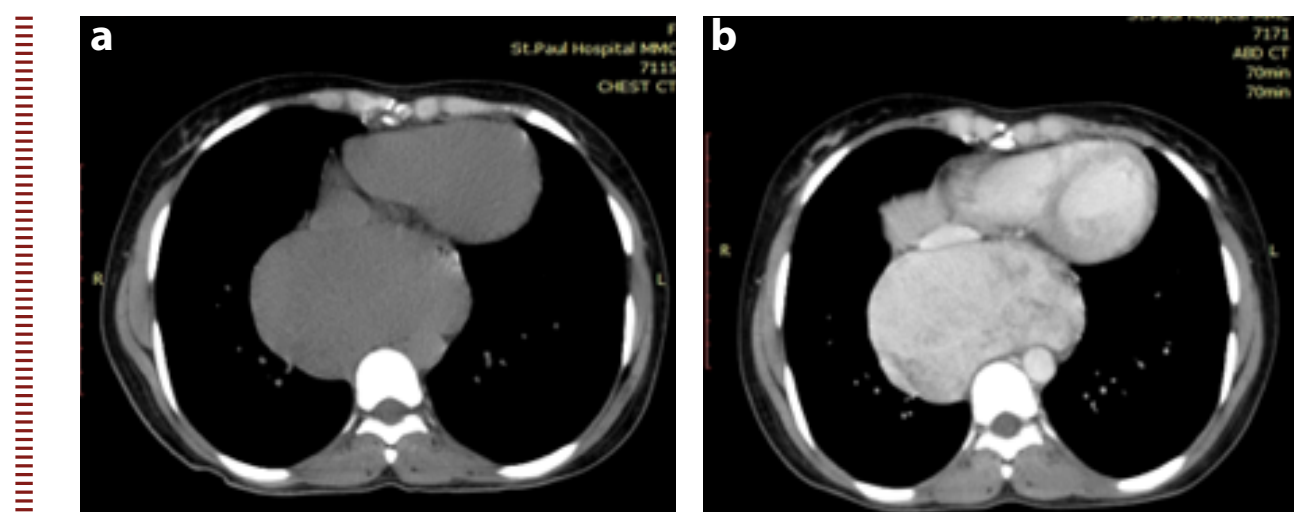

Figure 1. CT thorax before (a) and after (b) administrating of contrast medium demonstrating a well-defined $10 \times 6 \mathrm{~cm}$ hy-per enhancing para-esophageal mass.

\section{Case presentation}

A 26-year-old female with a small goitre was referred to our hospital for evaluation after experiencing 9 months of a dull aching pain in her left chest and flank associated with tingling in the same areas and weight loss. She denied any history of treatment for tuberculosis. The physical exam was unremarkable apart from the $2 \times 2 \mathrm{~cm}$ benign goitre. Chest $\mathrm{x}$-ray revealed a posterior mediastinal opacity. Computerized tomography (CT) of the thorax demonstrated a $10 \times 6 \mathrm{~cm}$, well-defined, hyperenhancing posterior mediastinal mass (Figure 1). A preliminary radiographic diagnosis of posterior mediastinal neurogenic tumour was made. Abdominal ultrasound and CT of the abdomen revealed no pertinent findings.

The patient underwent a right posterolateral thoracotomy. Intraoperatively, a highly vascular posterior para-oesophageal mediastinal mass was encountered. The mass was covered by mediastinal pleura, which was excised separately. The mass was not adherent to any mediastinal structure, 

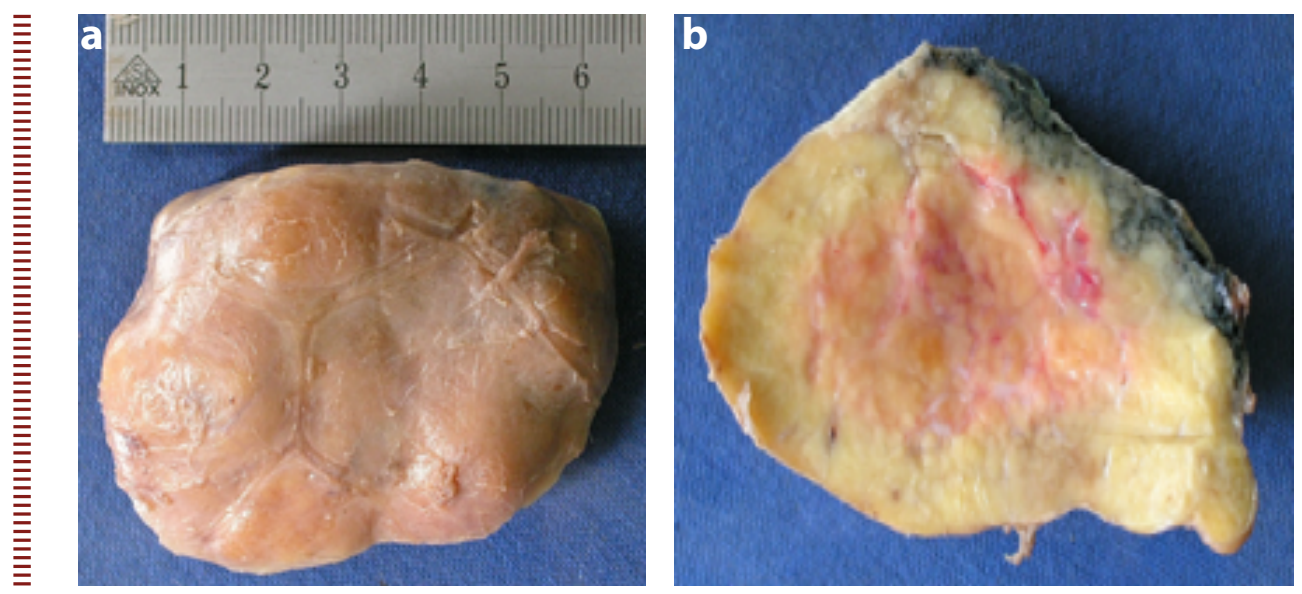

Figure 2. Gross appearance of the tumor, (a) lobular well circumscribed mas, (b) with central hemorrhage
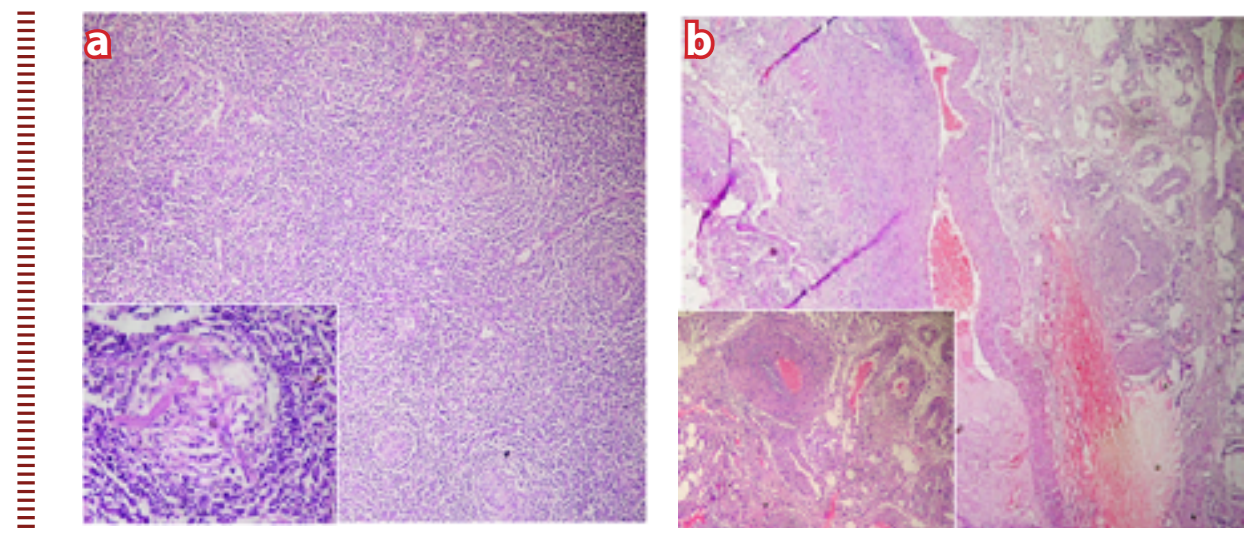

Figure 3. Angiofollicular hyperplasia (Castleman's Disease) of para-oesophageal lymph node (a) associat-ed with a hamartomatous vascular lesion (AV malformation) (b)
The majority of unicentric $\mathrm{CD}$ is located in the mediastinum (70\%) with posterior mediastinal $\mathrm{CD}$ being extremely rare. ${ }^{6-8}$ Review of the available literature revealed 10 cases of $\mathrm{CD}$, primarily arising from the posterior mediastinum, that were diagnosed as neurogenic tumours, much like our case. The presentation of our patient with pain and tingling increased our preoperative suspicion of a tumour of neurogenic origin.

To date, only 1 case series and 1 case report of $\mathrm{CD}$ discuss a vascular neoplasm complicating the disease. Gerald et. al. reported the development of vascular neoplasia in 7 cases of CD in 1990, with 1 being mediastinal. The authors postulated that angiogenic factor produced by the activated lymphoid tissue might contribute to the development of the vascular neoplasia. ${ }^{9}$ The case report by Chan et al. in 1994 discussed a case with a follicular dendritic cell tumour and vascular and it was enucleated, appearing smaller than the radiographic evidence suggested. Gross pathologic examination of the tumour revealed a tan-coloured, lobular, well-circumscribed mass (Figure 2). Thin sections under microscopy demonstrated hypervascular follicular hyperplasia (Figure 3a) and a hamartomatous vascular lesion with features of an arteriovenous (AV) malformation.

\section{Discussion}

CD was originally described by Benjamin Castleman in a 1954 case report $^{3}$ and a 1956 case series. ${ }^{4} \mathrm{CD}$ is a benign disease of the lymph nodes with characteristic nonclonal hyperplasia of the follicles. The condition is also referred to as benign giant lymphoma, angiofollicular lymph node hyperplasia, follicular lymphoreticuloma, lymphoid hamartoma, and giant cell lymph node hyperplasia. The rarity of the condition makes understanding of its epidemiology and precise aetiology difficult with all available information coming from case reports, case series, and expert opinions.

The incidence of $\mathrm{CD}$ is unknown, but there were more than 400 cases reported in the international literature as of $2001 .^{5} \mathrm{CD}$ affects males and females equally, and it is most commonly seen in the third decade of life; the plasmacytic type usually affects people in their sixth decade. neoplasm complicating intra-abdominal (mesocolon) CD. ${ }^{10}$ Hence, our case marks the ninth case of CD complicated by vascular neoplasm and only the second of mediastinal CD with vascular neoplasia.

There has been only 1 reported case of posterior mediastinal CD with a hypervascular tumour, which presented as a hypervascular lipomatous posterior mediastinal mass. The authors postulated the hypervascularity to be reactive in nature, with pathology demonstrating the typical hyaline vascular type of $\mathrm{CD}$ with no associated vascular lesion. ${ }^{11}$ Unique to our case, there was a component of hamartomatous vascular neoplasia (AV malformation) identified in addition to the hyaline vascular type of CD found on histology.

Clinically, CD is classified into 2 major types. The more common unicentric CD (two-thirds of cases) usually involves single lymph node stations of the mediastinum, abdomen, neck, or axilla. Multicentric CD involves multiple lymph nodes and other lymphoid structures, carrying a poorer overall prognosis than unicentric $\mathrm{CD}$. The precise cause of CD is unknown; however, the multicentric disease is associated with human herpesvirus 8 (Kaposi's sarcoma-associated herpes virus), found most commonly in HIV-infected individuals. ${ }^{12}$ Interleukin-6 (IL-6) is also described as 
an important factor in the pathogenesis of this disease. ${ }^{13-16}$ Multicentric disease has been associated with POEMS (polyneuropathy, organomegaly, endocrinopathy, monoclonal gammopathy, and skin changes) syndrome.

Histologically, CD is classified into 3 variants: hyaline vascular, plasmacytic, and mixed cellularity. ${ }^{1}$ The hyaline vascular variety is the predominant type identified in unicentric CD, and the plasmacytic histology is found in most cases of multicentric CD. ${ }^{1}$

The clinical manifestations are protean. CD has great variation in presenting signs and symptoms, determined by the extent of the disease, type of pathology, HIV status, extent of IL- 6 secretion, associated autoimmune phenomena, and overlap with POEMS syndrome. ${ }^{13}$ Unicentric disease can present incidentally or as a mass with local symptoms due to mass effect. Multicentric CD can present with enlargement of multiple lymph nodes throughout the body, hepatosplenomegaly, and systemic symptoms like fever, night sweats, weight loss and anorexia. Such cases can have derangements in a wide range of biochemical studies, including anaemia, elevated erythrocyte sedimentation rate, C-reactive protein, and organ function tests.

Diagnosis requires a tissue sample, often obtained via excisional biopsy, as small samples of isolated cells from a fine-needle aspiration may lead to diagnosis failure. ${ }^{1}$

There are no published randomized clinical trials that address CD management. Most of the literature is confined to small series or case reports, and it is difficult to make firm recommendations. ${ }^{17}$ Clinical staging guides treatment decisions and prognosis. The goals of the staging and pretreatment evaluation are to (a) determine whether the patient has unicentric or multicentric disease, (b) identify patients with systemic inflammatory manifestations of the disease, and (c) assess for the presence of HIV, as well as associated conditions and malignancies.

Complete surgical resection is 95\% curative with unicentric CD and affords resolution of constitutional symptoms, if present. Whenever surgical resection is not feasible, radiation therapy is an acceptable alternative..$^{7,13,17,18}$ Recurrences can occur in cases treated with incomplete resection for unicentric $\mathrm{CD}$ as late as 11 years later; therefore, long-term follow-up is warranted. ${ }^{7,19}$ Most of the publications regarding unicentric $\mathrm{CD}$ treated with complete surgical resection reported no recurrence. In our case, given the complete enucleation of the tumour and the histopathology findings lacking any adverse prognostic factors, we are fairly certain that our patient has an excellent prognosis with long-term follow-up. ${ }^{20}$

Treatment of multicentric CD is more complicated, ranging from multimodal approaches involving surgery and chemotherapy to targeted administration of monoclonal antibodies and steroids. Without any randomized studies, these treatment recommendations are based on limited case studies and case series.

\section{Conclusions}

$\mathrm{CD}$ is a rare benign lymphoproliferative condition and should be considered as a diagnosisfor for patients with benign lymphadenopathies. We have presented here a very rare disease in an unusual location, which mimicked a neurogenic tumour and was further complicated by a vascular malformation. Management relies up on determining the histologic and anatomic types of the disease and identification of associated pathologies, such as HIV. Unicentric CD has an excellent prognosis with complete excision, which was achieved in our patient.

\section{Acknowledgements}

I would like to acknowledge Prof. Schneider for the histological examination and accompanying photographs.

\section{Competing interests}

The author declares that he has no competing interests related to this work.

\section{References}

1. Roca B. Castleman's disease. A review. AIDS Rev. 2009 Jan-Mar;11(1):3-7

2. Ko SF, Wan YL, Ng SH, Lin JW, Hsieh MJ, Fang FM, et al. Imaging features of atypical thoracic Castleman disease. Clin Imaging. 2004 Jul-Aug;28(4):280-5. doi: 10.1016/S0899-7071(03)00202-X

3. Castleman B, Towne VW. Case records of the Massachusetts General Hospital; weekly clinicopathological exercises; founded by Richard C. Cabot. Case 40351. N Engl J Med. 1954 Sep 2;251 (10):396-400. doi: 10.1056/NEJM195409022511008.

4. Castleman B, Iverson L, Menendez VP. Localized mediastinal lymphnode hyperplasia resembling thymoma Cancer. 1956 Jul-Aug;9(4):822-30. doi: 10.1002/1097-0142(195607/08)9:4<822::AIDCNCR2820090430>3.0.CO;2-4.
5. Sarrot-Reynauld F. Castleman's disease [Internet]. In: Orphanet encyclopedia. Paris: Orphanet; c2001. Available from: https://www.orpha.net/data/patho/Pro/ en/Castleman-FRenPro3618.pdf.

6. Keller AR, Hochholzer L, Castleman B. Hyaline-vascular and plasma-cell types of giant lymph node hyperplasia of the mediastinum and other locations. Cancer 1972 Mar:29(3):670-83. doi: 10.1002/1097-0142(197203)29:3<670::AIDCNCR2820290321>3.0.CO;2-\#

7. Iyoda A, Yusa T, Hiroshima K, Fujisawa T, Ohwada H. Castleman's disease in the posterior mediastinum: report of a case. Surg Today. 2000;30(5):473-6. doi: $10.1007 / \mathrm{s} 005950050629$.
8. Eisenstat RS, Price DB, Rosenthal $A D$, Schuss AL, Katz DS. Thoracic epidural Castleman's disease. AJR Am J Roentgenol. 2002 Jan;178(1):208-10. doi: 10.2214/ajr.178.1.1780208.

9. Michaelides $M$, Nikolaidou $A$ Konstantinou D, Balis G, Tsitouridis I. Posterior mediastinal Castleman's disease presented as hypervascular lipomatous tumor. Hippokratia. 2011 Oct;15(4):361-2.

10. Gerald W, Kostianovsky M, Rosai J. Development of vascular neoplasia in Castleman's disease. Report of seven cases. Am J Surg Pathol. 1990 Jul;14(7):603-14. 
11. Stebbing J, Pantanowitz L, Dayyani F, Sullivan R, Bower M, Dezube BJ. HIVassociated multicentric Castleman's disease. Am J Hematol. 2008 Jun;83(6):498-503. doi: 10.1002/ajh.21137.

12. Chan JK, Tsang WY, Ng CS. Follicular dendritic cell tumor and vascular neoplasm complicating hyaline-vascular Castleman's disease. Am J Surg Pathol. 1994 May;18(5):517-25.

13. Chang Y, Cesarman E, Pessin MS, Lee F, Culpepper J, Knowles DM, et al. Identification of herpesvirus-like DNA sequences in AIDS-associated Kaposi's sarcoma. Science. 1994 Dec 16;266(5192):1865-9. doi: 10.1126/ science.7997879.

14. Soulier J, Grollet L, Oksenhendler E, Cacoub P, Cazals-Hatem D, Babinet P, et al. Kaposi's sarcoma-associated herpesviruslike DNA sequences in multicentric Castleman's disease. Blood. 1995 Aug 15;86(4):1276-80.
15. An J, Lichtenstein AK, Brent G, Rettig MB. The Kaposi sarcoma-associated herpesvirus (KSHV) induces cellular interleukin 6 expression: role of the KSHV latency-associated nuclear antigen and the AP1 response element. Blood. 2002 Jan 15;99(2):649-54. doi: 10.1182/blood. V99.2.649.

16. Chronowski GM, Ha CS, Wilder RB, Cabanillas F, Manning J, Cox JD. Treatment of unicentric and multicentric Castleman disease and the role of radiotherapy. Cancer. 2001 Aug 1;92(3):670-6. doi: 10.1002/1097-0142(20010801)92:3<670::AIDCNCR1369>3.0.CO;2-Q

17. van Rhee F, Stone K, Szmania S, Barlogie B, Singh Z. Castleman disease in the 21st century: an update on diagnosis, assessment, and therapy. Clin Adv Hematol Oncol. 2010 Jul;8(7):486-98.
18. Safford SD, Lagoo AS, Mahaffey SA. Preoperative embolization as an adjunct to the operative management of mediastinal Castleman disease. J Pediatr Surg. 2003 Sep;38(9):E21-3. doi: doi. org/10.1016/S0022-3468(03)00421-4.

19. Olscamp G, Weisbrod G, Sanders D, Delarue N, Mustard R. Castleman disease: unusual manifestations of an unusual disorder. Radiology. 1980 Apr;135(1):43-8. doi: 10.1148/radiology.135.1.7360978.

20. Talat N, Belgaumkar AP, Schulte KM. Surgery in Castleman's disease: a systematic review of 404 published cases. Ann Surg. 2012 Apr:255(4):677-84. doi: 10.1097/SLA.0b013e318249dcdc. 